\title{
The influence of anisotropic $F$ region ion velocity distributions on ionospheric ion outflows into the magnetosphere
}

Article

Published Version

Suvanto, K., Lockwood, M. and Fuller-Rowell, T. J. (1989) The influence of anisotropic $F$ region ion velocity distributions on ionospheric ion outflows into the magnetosphere. Journal of Geophysical Research, 94 (A2). pp. 1347-1358. ISSN 01480227 doi: https://doi.org/10.1029/JA094iA02p01347 Available at https://centaur.reading.ac.uk/38884/

It is advisable to refer to the publisher's version if you intend to cite from the work. See Guidance on citing.

Published version at: http://dx.doi.org/10.1029/JA094iA02p01347

To link to this article DOI: http://dx.doi.org/10.1029/JA094iA02p01347

Publisher: American Geophysical Union

All outputs in CentAUR are protected by Intellectual Property Rights law, including copyright law. Copyright and IPR is retained by the creators or other copyright holders. Terms and conditions for use of this material are defined in the End User Agreement.

www.reading.ac.uk/centaur 
Central Archive at the University of Reading

Reading's research outputs online 
THE INFLUENCE OF ANISOTROPIC F REGION ION VELOCITY DISTRIBUTIONS ON IONOSPHERIC ION OUTFLOWS INTO THE MAGNETOSPHERE

K. Suvanto

Blackett Laboratory, Impertal College, London

M. Lockwood ${ }^{1}$

Rutherford Appleton Laboratory, Chilton, Didcot, England

T. J. Fuller-Rowe11

University College, London

\begin{abstract}
The contribution to the fieldaligned ionospheric ion momentum equation, due to coupling between pressure anisotropy and the inhomogeneous geomagnetic field, is investigated. We term this contribution the "hydrodynamic mirror force" and investigate its dependence on the fon drift and the resulting deformations of the ion velocity distribution function from an isotropic form. It is shown that this extra upforce increases rapldly with ion drift relative to the neutral gas but is not highly dependent on the lon-neutral collision model employed. An example of a burst of flow observed by EISCAT, thought to be the Lonospheric signature of a flux transfer event at the magnetopause, is studied in detall and it is shown that the nonthermal plasma which results is subject to a hydrodynamic mirror force which is roughly $10 \%$ of the gravitational downforce. In addition, predictions by the coupled University College London - Sheffield University model of the lonosphere and thermosphere show that the hydrodynamic mirror force in the auroral oval is up to $3 \%$ of the gravitational force for $\mathrm{Kp}$ of about 3 , rising to $10 \%$ following a sudden increase in cross-cap potential. The spatial distribution of the upforce shows peaks in the cusp region and in the post-midnight auroral oval, similar to that of observed low-energy heavy ion flows from the Ionosphere into the magnetosphere. We suggest the hydrodynamic mirror force may modulate these outflows by controlling the supply of heavy tons to regions of ion acceleration and that future simulations of the effects of Joule heating on ion outflows should make allowance for it.
\end{abstract}

\section{Introduction}

Recently, Lockwood and Fuller-Rowe11 [1987a, b] have suggested a causal connection between nonthermal and bi-Maxwellian plasmas in the

\footnotetext{
${ }^{1}$ Also Visiting Honorary Lecturer at Blackett Jaboratory, Imperial College, London.
}

Copyright 1989 by the American Geophysical Union.

Paper number 88JA03091.

0148-0227/89/88JA-03091\$05.00 ionospheric $F$ region and sources of the heavy lons which are accelerated to several electron volts at greater altitudes and subsequently flow from the ionosphere into the magnetosphere. In order to look at this suggestion in more detail, this paper assesses the role of temperature anisotropy on plasma dynamics in an inhomogeneous geomagnetic field.

1.1. Observations of Nonthermal

and Bi-Maxwellian Plasmas in

the Auroral Ionosphere

The presence of non-Maxwellian fon velocity distributions in the auroral ionospheric $F$ region was predicted over a decade ago from

considerations of the effects of large lon drifts relative to the neutral gas for various models of the ion-neutral collisional process (see review by St.-Maurice and Schunk [1979]). Some retarding potential analyzer data from the AE-C satellite revealed non-Maxwellian plasma [St.-Maurice et a1., 1976], but the spatial/temporal ambiguity problem and the lack of sufficlent suitable data meant that the lifetime and occurrence of these distributions remained uncertain. Using the EISCAT incoherent scatter radar, and assuming a bi-Maxwellian ion velocity distribution, Lovhaug and F1P [1986] found very large fon temperature an1sotropies $\left(\mathrm{T}_{1 \perp} / \mathrm{T}_{1 \|}\right.$ of up to about 2.5 ) caused by enhanced ion flows during substorms. For these tristatic observations, the lon velocity distribution is sampled along three directions, and each would give a Maxwellian one-dimensional distribution of line-of-sight velocities if the three-dimensional distribution were bi-Maxwellian in form. The effect of a non-Maxwellian line-ofsight ion velocity on the spectra of the scattered signals was predicted theoretically by Raman et a1. [1981] and shown to increase rapidly with increasing aspect angle between the look direction and the magnetic fleld. At large angles to the field $\left(>50^{\circ}\right)$ the spectrum becomes triple humped, having one large central peak with only small shoulders at the Ion-acoustic frequency, whereas for small angles $\left(<30^{\circ}\right)$ the spectrum is the normal double-peaked one, characteristic of Maxwellian plasmas. Furthermore, these authors showed that the Ion temperature derived from the radar data by assuming a Maxwellian distribution would exceed 
the real average (or three-dimensional) one for a non-Maxwellian if the plasma is viewed at a large aspect angle. The old location of the SRI radar at Chatanika (now located at Sondrestromfjord) was Ideal for observing such spectra, as the auroral oval (where suffictently large flows are expected) could be observed at an angle to the field large enough to allow them to become apparent. Indeed, such spectra were observed in the Chatanika data (v. Wickwar, private communication, 1987), but it was impossible to unambiguously attribute them to non-Maxwellian effects as they could be mimicked by velocity changes within the intergration period or by velocity shears within the scattering volume. Definite identification was only recently achieved by Lockwood et al. [1987] by studying the effects of newly-discovered putative lonospheric signatures of flux transfer events at the magnetopause [Todd et al., 1986], observed by EISCAT using the monostatic UK-Polar experiment with a similar auroral viewing geometry to that for the old Chatanika radar site. Recently, Winser et al. [1987b] have used EISCAT Common Programme CP-3-E data to show that the aspect angle dependence of the spectral shape is as predicted by Raman et al. [1981] for the periods when the ion temperature anisotropy, as deduced assuming a bi-Maxwellian form, is larger than expected for the observed ion drift. These observations Indicate the presence of nonMaxwellian plasma.

The results of Lockwood et al. [1987; 1988a] showed that the non-Maxwellian plasmas persisted for as long as the ion velocity exceeded the predicted threshold (1.e. longer than 1 minute). Because this is larger than the expected time constants of small-scale processes which would act to destroy the non-Maxwellian velocity

distribution (ion-ion collisions, microinstabilities), it is expected that they should exist for large perlods of time wherever the relative ion-neutral velocity is sufficiently large. Indeed, Farmer et al. [1988] have reported spectra characteristic of nonthermal plasma observed by the UK-Polar experiment to persist for up to an hour. Lockwood and Fuller-Rowel1 [1987a, b] have predicted when this should occur, even for steady, moderate convection conditions (and discussed the effects of changes in convection), by making use of the coupled lonospherethermosphere UCL model. They have concluded that plasma should be continuously close to the nonthermal threshold in certain regions and suggested a possible connection with large flows of $\mathrm{O}^{+}$ions from the lonosphere into the magnetosphere along geomagnetic field lines in these regions.

1.2. Spatial Gradients and Ion-Neutral Coupling Terms in the Kinetic and Momentum Equations

Our aim is to quantify the effect of ion temperature anisotropy and magnetic fleld inhomogeneity on field-parallel lon flows and assess the 1mplications for modeling and observation of plasma dynamics. In this section we discuss our approximations concerning the kinetic and momentum equations. It is shown that within the approximation scheme to be adopted, the pressure force can be calculated to lowest order using the ion velocity distribution for a timeindependent, spatially homogeneous plasma. In other words, although spatial gradients are of interest in the fleld-parallel momentum equation it is consistent to neglect them in the kinetic equation in this approximation.

The kinetic equation in the $\overline{\mathrm{E}} \times \overline{\mathrm{B}} \mathrm{drift}$ frame is

$$
\begin{aligned}
\Omega \frac{\partial f}{\partial \theta} & =C(f)-\frac{\partial f}{\partial t}-\bar{v} \cdot \frac{\partial f}{\partial \bar{r}} \\
& -\frac{q}{m} E_{\|} \frac{\partial f}{\partial v_{\|}}-g \cdot \frac{\partial f}{\partial \bar{v}}
\end{aligned}
$$

where $f(\bar{r}, \bar{v}, t)$ is the ion velocity distribution function, $\Omega$ the lon gyrofrequency, $E_{\|}$the component of the electric field along the geomagnetic field, $\bar{g}$ the gravitational acceleration, and $\theta$ the gyrophase angle in velocity space; the term $C(f)$ accounts for lonneutral collisions. Coulomb collisions have been neglected because the plasma is only weakly ionized. The corresponding momentum equation describing field-aligned flows may be written as

$$
\begin{aligned}
& \mathrm{nm}\left[\frac{\mathrm{Du}}{\mathrm{Dt}}\right]_{\|}=-\nu \mathrm{nm}\left(\mathrm{u}_{\|}-\mathrm{u}_{\mathrm{n} \|}\right)-\nabla \cdot \overline{\overline{\mathrm{p}}} \| \\
& +\mathrm{nq} \mathrm{E}_{\|}+\mathrm{nmg}_{\|}
\end{aligned}
$$

where $\bar{u}$ and $\bar{u}_{n}$ are the ion and neutral drift speeds respectively, $D / D t=(\partial / \partial t)+\bar{u} .(\partial / \partial \bar{r})$ is the convective derivative, $\nu$ is the ion-neutral collision frequency for momentum transfer and the pressure tensor is defined by

$\bar{p}=m \int d^{3} \sqrt[v]{c} \bar{c} f \equiv n m\langle\bar{c} \bar{c}\rangle$

Here $\bar{c}$ is the random part of ion velocity and the angle brackets are defined to denote the ensemble average. In order to derive an expression for the pressure force, the ion velocity distribution has to be known. Some assumptions on the relative magnitudes of the terms in (1) and (2) are needed to enable analytical estimation of the effects caused by anisotropic temperature. The ratios of the last four terms on the right-hand side of (1) to the collistonal term can be characterized by the following dimensionless quantitites,

$$
\begin{aligned}
\varepsilon_{1} & =1 / \nu \mathrm{T} \\
\varepsilon_{2} & =\mathrm{v}_{\mathrm{th}} / \nu \mathrm{L} \\
\varepsilon_{3} & =\mathrm{qE} \mathrm{E}_{\mathrm{n}} / \nu \mathrm{mV} \mathrm{th} \\
\varepsilon_{4} & =\mathrm{g} / \nu V_{\mathrm{th}}
\end{aligned}
$$

where $\mathrm{L}$ and $\mathrm{T}$ are the length and time scales associated with spatial and time varlations, respectively, and $V_{t h}$ is the thermal speed of the ions. We now assume that as far as the form of the distribution function is concerned, Ionneutral collisions dominate over effects associated with spatial gradients, parallel 
electric flelds and gravitational effects. Also, the typical time scale $T$ for the temporal evolution of $f$ is assumed to be much larger than the relaxation time associated with collistons. In other words, $\varepsilon_{1}, \varepsilon_{2}, \varepsilon_{3}$ and $\varepsilon_{4}$ must all be $\ll 1$. To lowest order, the distribution function is thus determined by the magnetic fleld and ion-neutral collisions :

$$
\Omega \frac{\partial f}{\partial \theta}=C(f)
$$

In the high-latitude $F$ region $\nu / \Omega \ll l$, so that $f$ can be written as the sum of a gyrotropic velocity distribution $\mathrm{f}^{0}$ and a correction $\delta \mathrm{f}$,

$$
f=\mathrm{f}^{0}+\delta \mathrm{f}
$$

where $\delta f$ is of order $v / \Omega$, as pointed out by St.Maurice and Schunk [1979]. In general, the latter term on the righthand side of (6) can be regarded as the correction corresponding to all the neglected terms in (1), $f^{0}$ being the gyrotropic distribution for spatially homogeneous and timeindependent plasma with rare ion-neutral collistons. It should be noted, however, that neglecting the spatial and time derivatives in (1) is not to say that $f$ should be independent of $\bar{r}$ and $t$. Merely, we require these derivatives to be small compared with the collisional term.

Although spatial gradients are assumed to be negligible in the kinetic equation, they may be important in the momentum equation (2). This can be seen as follows. The pressure force term in (2) is of the order of $\mathrm{nmV}_{t h}{ }^{2} / \mathrm{L}$ so that its ratio to the lon-neutral coupling term in the same equation is of order $\left(v_{t h}{ }^{2} / \nu L\left|u_{n}-u_{n \eta}\right|\right)$. Our assumption $\varepsilon_{2} \ll 1$ implies that $v_{t h} / \nu L \ll 1$; the above ratio of the pressure and frictional forces can still be comparable to unity because the field-aligned component of the relative lonneutral drift is much smaller than the ion thermal velocity in our region of interest.

Finally, it should be pointer out that we can put $f=f^{0}$ in the equation (3) for the pressure tensor. The consistency of this approximation is verified by noting that the pressure force obtained this way is of the order of $\mathrm{nmV}^{2} / \mathrm{L}$, the correction due to the omitted terms in ( $\mathrm{F}$ ) being approximately $(\nu / \Omega) \mathrm{nmV}_{\mathrm{th}}{ }^{2} / \mathrm{L}$. The ratio of the correction term to the zeroth-order term is $\ll 1$ as 1t should be.

Note that the use of a relaxation collision model leads to the result that $\mathrm{f}^{0}$ is simply the neutral velocity distribution averaged over the gyrophase [Ott and Farley, 1975] so that $u_{1}=u_{n}$ in the approximation $f=f^{0}$. However, this result cannot be used in the frictional term of (2) because this term contains the "large" factor $v$ (remember our ordering $\varepsilon_{1} \ll 1 ; 1=1, \ldots, 4$ ) and, consequently, the relative fleld-aligned ionneutral drift speed must be evaluated to a higher degree of accuracy.

1.3. Ion Outflows From the Ionosphere Into the Magnetosphere

Several recent reviews have discussed the great variety of low-energy ionospheric ion outflows into the magnetosphere which have been observed [Moore, 1984; Lockwood, 1986; Yau and Lockwood,
1988; Horwitz, 1987]. The importance of these flows to magnetospheric plasma composition has been underlined by Chappell et a1. [1987] who determined that the typical ion densities in most regions of the magnetosphere can be accounted for by the lonospheric ion outflows alone. The mechanism which injects most lons into the magnetosphere is the "classical" polar wind, a flow of light lons ( $\mathrm{H}^{+}$and $\mathrm{He}^{+}$) driven at high and middle latitudes by normal ionospheric plasma density and temperatures via the charge separation, "ambipolar," field-aligned electric fleld. However, much interest has been focused on low-energy (several eV) heavy ion additions to the polar wind, observed to orginate from the auroral ionosphere, which are more variable than the classical polar wind and hence can act to modulate magnetospheric ion composition. Two distinct sources of such tons have been identifled. First, the dayside cleft gives large, continuous fluxes of "upwelling ions" [Lockwood et al., 1985a, b, c; Moore et al., 1986a], which are subsequently dispersed throughout the polar magnetosphere in the "cleft ion fountaln" by the convection electric fleld [Lockwood et a1., 1985b; Horwitz and Lockwood, 1985]. Second, low-energy heavy Ions are observed in the nightside auroral oval with a variety of pitch angles and energies [e.g., Yau et al., 1985].

In addition to these observations of Ionospheric heavy lons in the low-altitude polar magnetosphere, a varlety of observations of exceptionally large (i.e., greater than required for the classical polar wind) and warmed lon flows have been made in the auroral ionosphere. Transversely heated $0^{+}$ions have been detected by ion mass spectrometers on satellites [Klumpar, 1979] and rockets [Whalen et a1., 1978; Yau et al., 1983; Moore et al., 1986b] and enhanced upward flows of plasma of energy $<1 \mathrm{eV}$ have been reported from topside sounder data [Lockwood and Tither1dge, 1981; Lockwood, 1982], from incoherent scatter data [Farmer et al., 1984; Winser et al., 1987a], and from low-altitude satellite mass spectrometers [Lockwood et al., 1985c; Tsunoda et a1., 1985; Heelis et al., 1984; Roux et a1., 1985]. In all these cases, the authors have suggested these enhanced Ionospheric upflows are connected with heavy lonospheric lon flows into the magnetosphere, and in the case discussed by Lockwood et al. [1985c], Ions observed in the magnetosphere were traced back to an ionospheric source at the location where the lonospheric upflow was simultaneously observed.

\section{Hydrodynamic Mirror Force}

In this section, we discuss the pressure force on the ions. As shown in section 1.2, the ion velocity distribution function can be assumed to be gyrotropic; the pressure tensor then takes the form (compare, e.g., with Clemmow and Dougherty $[1969$, p. 351])

$$
p_{i j}=p_{\|} b_{1} b_{j}+P_{\perp}\left(\delta_{1 j}-b_{i} b_{j}\right)
$$

in a Cartesian coordinate system Here $\hat{b}$ is the unit vector parellel with the magnetic field. The pressure force per unit volume is found from (7) by taking the spatial divergence; finally, we 
estimate the force of assuming a radial magnetic field, $\bar{B}(\bar{r})=B(r) \hat{r}$. The result is

$-\nabla \cdot \overline{\bar{p}}=\left[-\frac{\partial p_{n}}{\partial r}+p_{\|} \frac{d B / d r}{B}-p_{\perp} \frac{d B / d r}{B}\right] \hat{r}$

The subscripts refer to the directions parallel with and perpendicular to the geomagnetic field respectively. We note in passing that this expression can be given a simple physical interpretation. The first two terms on the righthand side of equation (8) arise from the fact that a fluid element constrained to move in a flux tube sees a nett force because of variations in (1) pressure and (2) the flux tube cross-sectional area, which is proportional to $1 /$ B (force = pressure $x$ area). The third term is numerically equal to the expectation value of the effective force (per unft volume) associated with magnetic mirroring in single particle dynamics with the guiding-center approximation. From (8) we find that the force per unit volume due to magnetic field inhomogeneity and pressure anisotropy, which will be referred to as the "hydrodynamic mirror force", is given by

$$
F_{m}=n k_{B}\left(T_{\|}-T_{1}\right) \frac{d B / d r}{B}
$$

where the parallel and perpendicular temperatures are defined by

$$
\begin{aligned}
& \frac{1}{2} \mathrm{k}_{B} \mathrm{~T}_{\|}=\frac{1}{2} \mathrm{~m}\left\langle\mathrm{c}_{\|}{ }^{2}\right\rangle \\
& \mathrm{k}_{\mathrm{B}} \mathrm{T}_{\perp}=\frac{1}{2} \mathrm{~m}\left\langle\mathrm{c}_{\perp}{ }^{2}\right\rangle
\end{aligned}
$$

Note that the force on an Ion of a given species, in a given magnetic field, depends only on the perpendicular and parallel temperatures of the specles, not the other details of the velocity distribution function.

\subsection{Hydrodynamic Mirror Force for a}

Non-Maxwellian Ion Velocity Distribution

St.-Maurice and Schunk [1979] used a variety of different models for ion-neutral collistons to evaluate the ion velocity distribution function in the case of a supersonic ion flow through the neutral atmosphere; it was found that the kinetic equation with a simple relaxation model for ionneutral collisions provides a closed-form solution for the distribution function in the limit where spatial and time derivatives can be neglected and ion-neutral collisions are rare, $v / \Omega \ll 1$. Also, the plasma is assumed to be linearly stable. This form of the distribution function is characterized by two physical parameters, the Mach number (the ratio of the relative Ion-neutral drift velocity and the neutral thermal speed), $D^{\prime}$, and the neutral temperature $T_{n}$. The model exaggerates non-Maxwellian features because of its backscattering nature; it can be used to approximate resonant charge exchange (also an Idealization) between 0 and $0^{+}$and other collisional processes as far as distortions of the field-perpendicular part of the ion velocity distribution function is concerned. A major shortcoming of this model is the fact that no distortions from a Maxwellian shape are predicted in the field-parallel direction. Barakat et a1.
[1983] studied the formation of non-Maxwellian velocity distributions using different kinds of collision models in their Monte Carlo simulations. They found that similar departures from a Maxwellian as predicted by the simple relaxation model could be produced by using a more realistic collision model allowing for polarization interactions, provided $D^{\prime}$ was larger than for the relaxation model. This suggested that the qualitatively good relaxation model could be improved by scaling the parameters $D^{\prime}$ and $T_{n}$. The approach had actually been used by Raman et $\mathrm{n}$ al. [1981] who replaced $D^{\prime}$ and $T_{n}$ by adjustable parameters $\mathrm{D}^{*}$ and $\mathrm{T}^{*}$ which are to be determined experimentally, as done by St.-Maurice et al. [1976] for satellite retarding potential analyzer data or recently by Moorcroft and Schlegel [1988] for EISCAT data using the spectral synthesis routine by Raman et al. [1981]. The approach has also been justifled analytically by Hubert [1984]. We will refer to this semfemptrical extension of the theory as the generalized relaxation model. It should be noted that even this generalization does not allow for any distortions from a Maxwellian shape in the field-parallel direction. For the results of Barakat et a1. [1983, Table 1] we can estimate that $D^{*} / D^{\prime}>0.5$, because the collision model allowing for both charge exchange and polarization produces more non-Maxwellian features for the electric field strength of 200 $\mathrm{mV} / \mathrm{m}$ than the pure relaxation model for $100 \mathrm{mV} / \mathrm{m}$. "Non-Maxwellian features" may be quantified by the ratio $f_{m} / f_{o}$, where $f_{m}$ is the maximum value of the distribution function and $f$ the value of the distribution function at $\overline{\mathbf{v}} \stackrel{0}{=} 0$. From the temperature anisotroples modelled by Barakat et al. [1983], $D^{*} / D^{\prime}$ - 0.67 for lower ffeld strengths, roughly consistent with the observations of Moorcroft and Schlegel [1988].

However, the assumption of a linearly stable plasma does not hold for very large drifts. The distribution function discussed above has been predicted to become unstable to the PostRosenbluth [Ott and Farley, 1975; St.-Maurice and Schunk, 1978] and ion cyclotron microinstability [Lakh1na and Bhatia, 1984; Suvanto, 1988a] if $D^{*}$ is larger than about 1.3. The distribution function itself will be modified by interactions between the particles and the large-amplitude waves associated with the instability [Suvanto, 1988b]. St.-Maurice [1978] has argued that the plasma will become only marginally unstable because of the wave-induced diffusion in velocity space. This may explain the behavior of $D^{*} / D^{\prime}$ as

a function of $D^{\prime}$ (see section 2.3).

The generalized relaxation model, as employed by Raman et al. [1981], gives

$$
\begin{aligned}
& \mathrm{T}_{\|}=\mathrm{T}^{*} \\
& \mathrm{~T}_{\perp}=\mathrm{T}^{*}\left(1+\mathrm{D}^{* 2}\right) \\
& \mathrm{T}_{1}=\mathrm{T}^{*}\left(1+\frac{2}{3} \mathrm{D} *^{2}\right)
\end{aligned}
$$

where $T_{1}$ is the average (or three-dimensional) ion temperature. Using arguments similar to those presented in section 1.2 , one can show that the ion-neutral coupling term can be regarded as the dominant one in the ion energy equation, which then takes the familiar form 


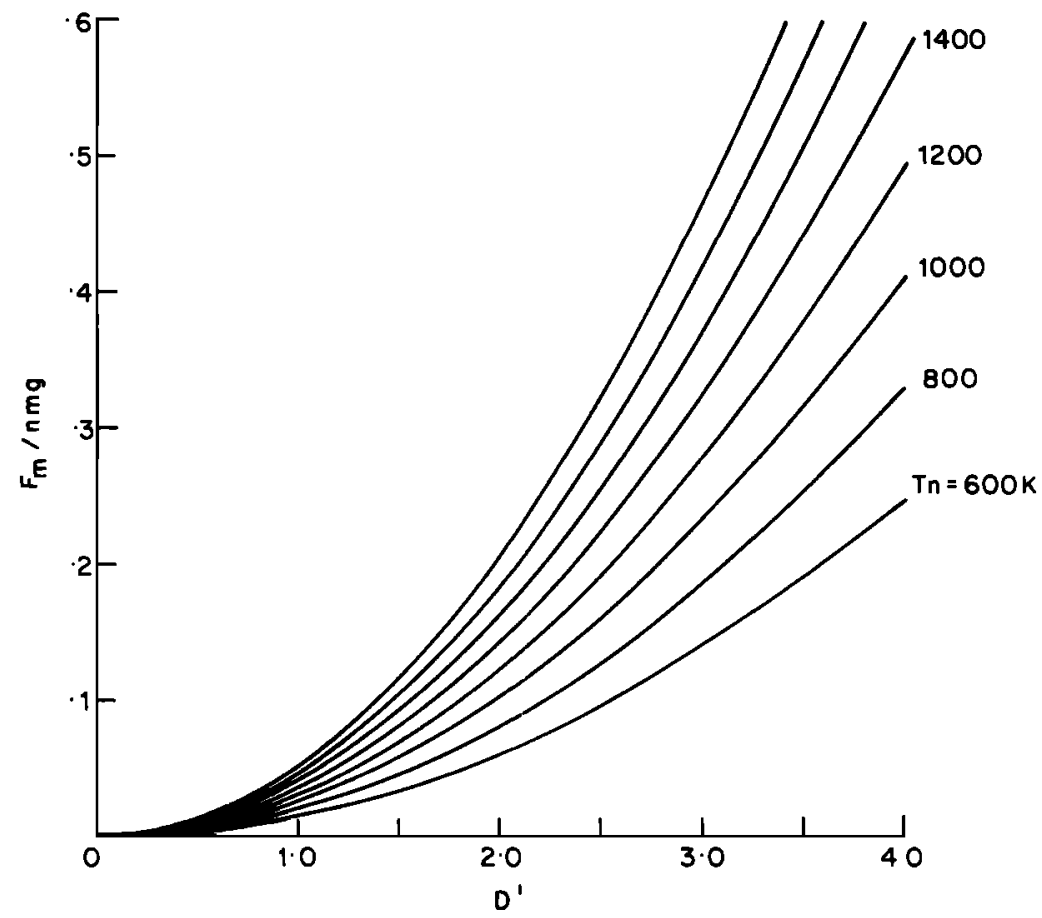

Fig. 1. The hydrodynamic mirror force for the pure relaxation model, as a fraction of gravity and as a function of the Mach number D'.

$$
T_{1}=T_{n}\left(1+\frac{2}{3} D^{\prime 2}\right)
$$

Here $T_{n}$ is the nautral temperature. The hydrodynamic mirror force associated with a nonMaxwellan distribution is found from (9), (11), and (12) to be

$\mathrm{F}_{\mathrm{m}}=\mathrm{nk}_{\mathrm{B}} \mathrm{T}_{\mathrm{n}}\left[\frac{1+\frac{2}{3} \mathrm{D}^{\prime 2}}{1+\frac{2}{3} \mathrm{D}^{*^{2}}}\right] \mathrm{D}^{*^{2}} \frac{3}{\mathrm{r}}$

where $B$ has been assumed to be proportional to $\mathbf{r}^{-3}$.

\subsection{Hydrodynamic Mirror Force as}

\section{a Function of Drift}

We now can investigate the magnitude of the hydrodynamic mirror force as a function of the relative ion-neutral drift speed. Figure 1 assumes the pure relaxation model $\left(D^{*} / D^{\prime}=1\right)$ for D' between 0 and 4 (see section 2.4 for predictions of $D^{\prime}$ values) and $F_{m}$ is shown for different values of the neutral temperature, and as a fraction of the gravitational downforce (nng). For the typical neutral temperature $\mathrm{T}_{\mathrm{n}}=1000 \mathrm{~K}$ the extra upforce is more than $10 \%$ of gravity if $D^{\prime}>2$. Figure 2 shows $\left(F_{m} / n m g\right)$ as a function of $D^{*} / D^{\prime}$ (roughly speaking, as a function of the collision model) for five fixed values of $D^{\prime}$. Clearly, $F_{m}$ maximizes at $D^{*} / D=1$, corresponding to the pure relaxation model. It is interesting to consider whether deviations from this collision model affect the value of $F_{m}$ seriously. For $D^{\prime}=1$, the magnitude of $F_{m}$ at $D^{*} / D^{\prime}=0.5$ is only $40 \%$ of the maximum value but for
$D^{\prime}=4$ the corresponding figure is as much as $80 \%$. We conclude that especially for large drifts, the value of the hydrodynamic mirror force is not very senstive to the collision model used. It should be noted that, this is true only for the generalized relaxation model, which may overestimate the temperature anisotropy and thus the magnitude of the hydrodynamic mirror force.

\subsection{Hydrodynamic Mirror Force}

in a Flow Burst Event

There is very little data available concerning the possible values of $D^{*} / D^{\prime}$ in the real lonosphere. Figure $3 a$, which is based on fits from RPA data [St.-Maurice and Schunk, 1979] and fits to EISCAT spectra, during the flow burst event described by Todd et a1. [1986], shows the estimated dependance of $D^{*} / D^{\prime}$ on $D^{\prime}$. The values of $D^{\prime}$ can be evaluated from the EISCAT data because of two important features of the flow burst events. The first is that for this event the fon flow is largely aligned with the radar ine-of-sight (see discussion given by Lockwood et al. [1988a] on this event) and the second is that the duration of the burst of enhanced flow is short compared with the response times of the neutral winds, composition and temperature. Consequently, the fon and neutral velocities within the flow burst are known from the fon velocities observed within and around the burst, respectively (the latter being almost zero). Hence the relative Ion-neutral drift, $V_{d}$, can be computed. In addition, the intercepts of regression fits of observed ion temperature (derived assuming a Maxwellian plasma) as a function of the square of the observed ion velocity, yleld the neutral temperature for each scattering volume [see Lockwood et al., 1987]. 


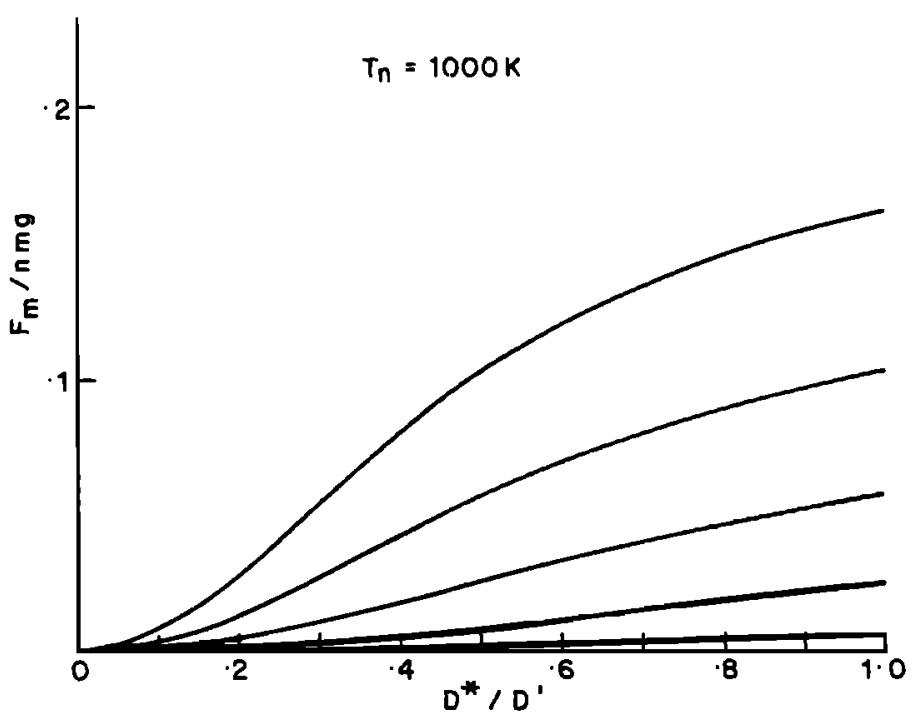

Fig. 2. The hydrodynamic mirror force as a function of the ratio $D^{*} / D^{\prime}$ associated with deviations from the relaxation collision model.

Hence the only unknown in $D^{\prime}$ is the neutral mass which 18 assumed to be 16 amu $\left(0^{+}\right)$. The uncertainties in $D^{\prime}$ are estimated from the experimental error in ion velocity and the error in $T_{n}$ (computed from the regression fits at the $2 \sigma$ leve1). The values of $D^{*}$ are computed by fits of the Raman et al. spectra to the observed spectra (both shown In Figure 2 of Lockwood et a1. [1988a] and should be regarded as having an error of roughly 0.1 . For small drifts, $D^{*} / D^{\prime}$ is almost constant and close to 1 ; at $D^{\prime} \sim 1.3$ the ratio falls off to about 0.7 but remains larger than 0.5 for $D^{\prime}<2.5$. It is interesting to note that these data appear to show the value of $D^{*}$ increasing to (a)

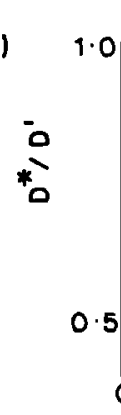

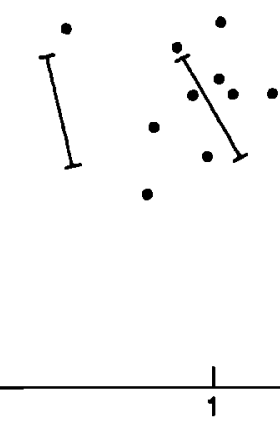

(b)

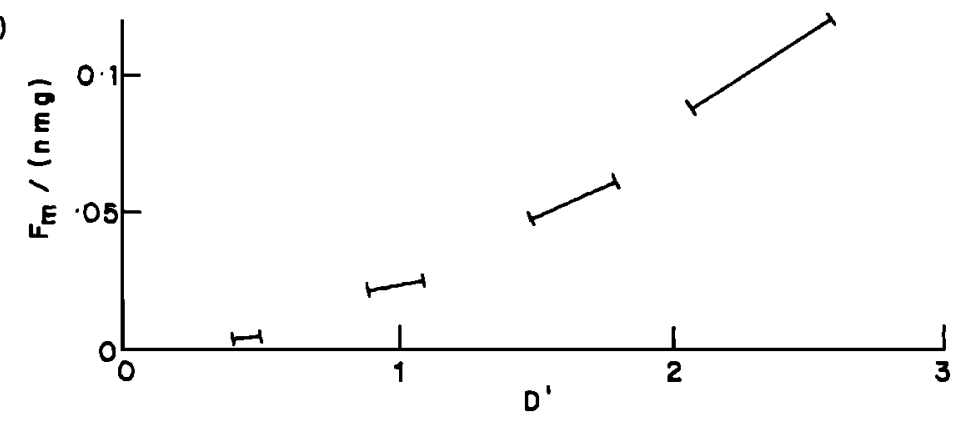

F1g. 3. (a) fits to the EISCAT data presented by Lockwood et al. [1987a,b], as a function of $D^{\prime}$ (see text). Also shown are values from the RPA data presented by St.-Maurice et al. [1976]. (b) The hydrodynamic mirror force as a function of $D^{\prime}$ for the $D^{*} / D^{\prime}$ values given in Figure 3a. The error bars reflect the uncertainty in D' alone. 
close to the limft (D* 1.3) where the ion velocity distribution is predicted to become unstable to the Ion cyclotron and Post-Rosenbluth instabilities due to the temperature antsotropy and the positive slope of the perpendicular distribution. These EISCAT data are thought to show the lonospheric signature of a flux transfer event (FTE) [Todd et al., 1986] and the plasma was shown to be driven into a non-Maxwellian by Lockwood et al. [1987, 1988a]. The variation of the hydrodynamic mirror force with $D^{*} / D^{\prime}$, taken from figure $3 \mathrm{a}$, is shown in Figure $3 \mathrm{~b}$. The magnitude of the force exceeds $10 \%$ of gravity for $D^{\prime}=2.5$, observed at the centre of the FTE. This value of $D^{\prime}$ is somewhat larger than the predicted in the centre of an lonospheric signature of an FTE by Lockwood et al. [1988b], however, it is comparable with that predicted by these authors for the region of close field lines on either flank of the FTE.

Lockwood et al. [1988b] point out that both the hydrodynamic mirror force calculated here and the effect of a rise in the field-parallel ion temperature due to the transient burst of Joule heating which accompanies the FTE (as predicted for a homogeneous geomagnetic field by Gombosi and Killeen [1987]) should drive upward flows of ions and any such ions which are subject to further acceleration (to $~ 100 \mathrm{eV}$ energies) can reach the dayside magnetopause and should be present on the open flux tubes of the centre of the FTE and on closed flux tubes in the wake of the FTE. They do indeed find such fons in examples observed by the AMPTE UKS satellite where the FTE is thought to have been on the magnetopause and driving ionospheric ion flows for longer than the transit time of the ions from the lonosphere to the magnetopause. If the source of these ions is indeed the ionospheric FTE signature, the relative contribution of hydrodynamic force and transient Joule heating is not yet known.

2.4. Global Predictions of Hydrodynamic Mirror Force

Lockwood and Fuller-Rowell [1987a; b] have presented predictions of the spatial distribution of $D^{\prime}$ and $T_{1}$ from the three-dimensional, timedependent, UCL-Sheffield University global model of the coupled ionosphere-thermosphere system [Fuller-Rowell et al., 1987]. In this paper we make use of these predictions to evaluate the hydrodynamic mirror force. The model selfconsistently evaluates the plasma densities and temperatures and the neutral wind, temperature and composition for assumed patterns of the convection electrlc field and auroral particle precipitation. For a given location, UT, magnetic activity and time of year, all the parameters in $D^{\prime}$ can be evaluated for the patterns adopted. The results presented by Lockwood and Fuller-Rowell were for December solstice and a solar F10.7 flux index of 165 (near sunspot maximum) and for a negative $B$ component of the interplanetary magnetic field, simulated by using the Heppner and Maynard [1983] A-2 model of convection equipotentials in the northern hemisphere and the B- 2 model in the southern hemisphere (reproduced in Flgure 7 of Rees et a1. [1985]). Figure 1 of Lockwood and Fuller-Rowell [1987b] shows results for $D^{\prime}$ for two sets of conditions. First, moderately quiet conditions $\left(K_{p} \sim 3\right)$, were simulated by using a TIROS auroral activity level of 7 [Fuller-Rowe11 and Evans, 1987] with a cross-cap potential of 76 $\mathrm{kV}$ and allowing the model to attain steady state in a diurnal sense. The other set of conditions was for immediately followwing a southward turning of the Interplanetary magnetic field, in that the cross-cap potential ts increased to $152 \mathrm{kV}$, the model having achieved steady state immediately prior to the increase for the quiet conditions (76 $\mathrm{kV}$, TIROS leve1 7). In the case with this transient increase of cross-cap potential, it is assumed the thermospheric winds and composition have not had sufficient time to respond, nor has the polar cap radius in accordance with Faraday's law (as described by Siscoe and Huang [1983] and lockwood et al. [1986a]). Increases in cross cap potential and subsequent expansion of the polar cap have recently been reported by Lockwood et a1. $[1986 \mathrm{a}, \mathrm{b}]$, and the response of the convection Ion flow speeds to IMF $B_{7}$ variations have been discussed by Rishbeth et al. [1985] and Etemadi et a1. [1988].

In this section it is assumed that $D^{*}$ is roughly equal to $D^{\prime}$. Table 1 of Lockwood and Fuller-Rowell [1987b] shows that for $0^{+}$Ions at $300 \mathrm{~km}, D^{\prime}$ is everywhere less than about 0.9 for the quiet conditions, this maximum value rising to near 1.8 following the transient increase in cross-cap potential. Figure $3 a$ indicates that $D^{*}$ should be roughly equal to $D^{\prime}$ for the range of $D^{\prime}$ predicted for the quiet condition $\left(\begin{array}{lll}0 & D^{\prime} & 0.9\end{array}\right)$ but the use of $D^{*}=D^{\prime}$ may not be valid for the peak $D^{\prime}$ predicted after the transient convection enhancement. However, Figure $3 a$ indicated that for $D^{\prime}$ of $1.8, D^{*} / D^{\prime}$ is roughly 0.7 , and Figure 2 shows that the hydrodynamic mirror force at $D^{*} / D^{\prime}$ $=0.7$ is more than $90 \%$ of 1 ts value for $D^{*} / D=$ 1.0. Hence we estimate that the adoption of $D^{*} / D^{\prime}$ $=1$ will not cause an over-estimation of the upforce of more than $10 \%$.

Figure 4 shows the hydrodynamic mirror force predicted by the UCL-Sheffield model, using (13) with $D^{*}=D^{\prime}$. The values for $0^{+}$ions at a constant pressure level which is everywhere very close to an altitude of $300 \mathrm{~km}$, and the upforce is shown as a ratlo of the gravitational downforce on the Ions to give some estimation of the importance of the upforce due to the Inhomogeneous magnetic field in the fon momentum equation. Each contour plot is in a geographic latitude - solar local time frame and is a snapshot for $18 \mathrm{UT}$ and corresponds to the $D^{\prime}$ plots given in Figure 1 of Lockwood and Fuller-Rowe11 [1987b]. Figures 4a and $4 \mathrm{~b}$ show the predictions for the quiet, steady state conditions for the north and south (winter and summer) polar reglons respectively. Figures $4 \mathrm{c}$ and $4 \mathrm{e}$ show the equivalent plots for immediately after the translent convection enhancement. For the quiet conditions, the additional upforce is everywhere less than $2.7 \%$ of the gravitational downforce in winter and less that $1.7 \%$ in summer. W1 thout modeliling of the plasma dynamics along the flux tube, which is beyond the scope of this paper, it is not clear if this is a significant factor in terms of driving ion upflows. The peak upforce is found in the dayside auroral throat region, where the large westward neutral winds established in the afternoon auroral oval by ton drag meet the eastward convecting plasma of the morning sector; 

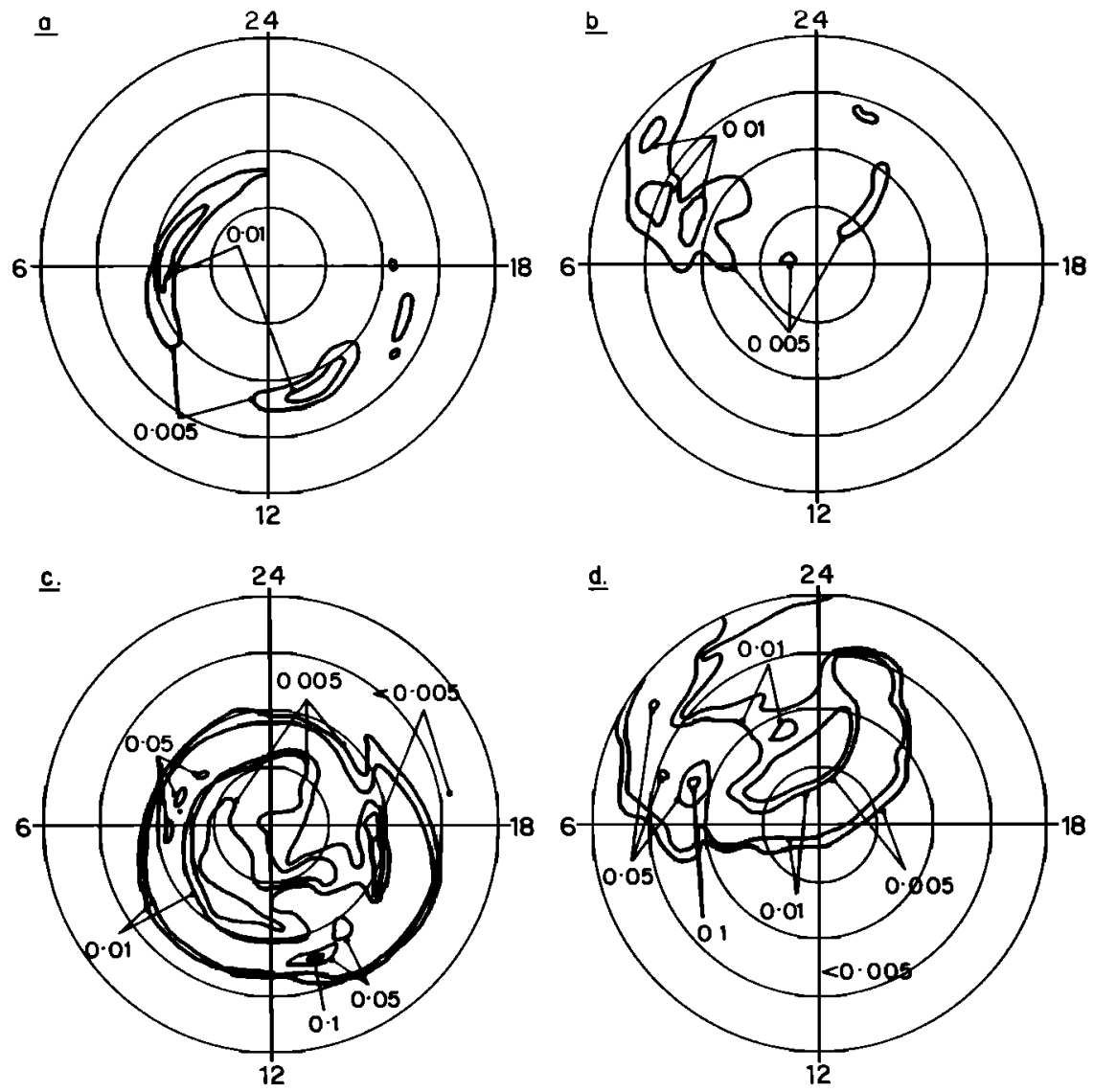

Fig. 4. Predicted values of the hydrodynamic mirror force on $0^{+}$ions at $300 \mathrm{~km}$ for 1800 UT and December solstice with $F 10.7=165$ and $B \quad 0$. Contours of $F_{m} / \mathrm{nmg}$ are shown as a function of solar local time (SLT) and geographic latitude over the range $50^{\circ}-90^{\circ} ; 4 \mathrm{a}$ and $4 \mathrm{c}$ are for the northern (winter) hemisphere and $4 \mathrm{~b}$ and $4 \mathrm{~d}$ are for the southern (summer) hemisphere. For $4 \mathrm{a}$ and $4 \mathrm{~b}$ the cross-cap potential is $76 \mathrm{kV}$ and the lonosphere-thermosphere system has achieved steady state; $4 \mathrm{c}$ and $4 \mathrm{~d}$ show the upforce immediately after an increase from 76 to $152 \mathrm{kV}$ under the same conditions.

as such flows are almost completely oppositely directed, the lon drift relative to the neutral gas is roughly the arithmetic sum of the neutral and ion speeds. Note that at this UT the throat is after 1200 SLT for the northern hemisphere and before 1200 SLT in the southern, but in an MLTinvariant latitude frame it is in the pre-noon sector in both cases (see convection patterns given in Figure 7 of Rees et a1. [1985]). The second, smaller peaks of the upforce are found in the dawn cell auroral oval. These are not as marked as the corresponding peaks in $D^{\prime}$, because $T$ is not as large as in the cusp region (see Flgure lc of Lockwood and Fuller-Rowe11 [1987a]). However, the higher $T_{n}$ in the summer hemisphere causes the upforce to be $1.5 \%$ of gravity in the dawn oval, compared with only $1 \%$ in winter. The origin of the dawn-dusk asymmetry in $D^{\prime}$ in the auroral oval has been discussed by Lockwood and Fuller-Rowell [1987a, and references therein].

Whether or not these upforces are significant in terms of ion dynamics, comparison of Figures $4 \mathrm{c}$ and $4 \mathrm{e}$ with Figures $4 \mathrm{a}$ and $4 \mathrm{~b}$ shows that dramatic increases are caused by the transtent increase in convection. For these cases the upforce rises to
$10 \%$ of gravity in both hemispheres in the cusp. The upforce in the dawn auroral oval is not enhanced to the same extent.

\section{Discussion and Conclusions}

We have studied the effect of an anisotropic ton velocity distribution on field-aligned ion flows in the high latitude tonosphere. Such distribution functions produce an additional upward force on F region plasma (between about 200 and about $500 \mathrm{~km}$ altitude) that is usually neglected in numerical simulations of ion dynamics and densities. It 1 s found that the value of $D * / D^{\prime}$ does not greatly affect this upforce. The magnitude of the hydrodynamic mirror force increases rapldly with the Mach number $D^{\prime}$.

We have Investigated the magnitude of the upforce within a flow burst event, observed by the EISCAT radar and shown by Todd et al. [1986] to be fully consistent with the expected lonospheric signature of a flux transfer event. It is found that in the center of this event the lon drift is sufficlently large for the hydrodynamic mirror force to become as large as $10 \%$ of the 
gravitational downforce on $0^{+}$1ons at $450 \mathrm{~km}$ altitude. Such a large factor would appear to be too large to ignore in the study of ion dynamics and we recommend future simulations should allow for such effects. The increased upforce is applied transiently in this case (for less than about $5 \mathrm{~min}$ ).

In addition, we have made use of the UCLSheffield University coupled model of the Ionosphere-thermosphere system to study this effect under more stable conditions. For moderate geomagnetic activity (Kp 3) we find that the peak upforce is only about $3 \%$ of gravity in the cusp region $1 \mathrm{n}$ winter and $2 \%$ in summer. However, if the cross-cap potential then suddenly rises from 76 to $152 \mathrm{kV}$ (due to a strong southward turning of the IMF) these values rise to near $10 \%$, similar to the value deduced for the FTE signature event. In this case the large upforce could be present in the cusp for a period of up to several hours while the neutral wind and plasma convection patterns respond to the change, and the upforce ratio would gradually decline to a value not much greater than the $2-3 \%$ prior to the convection enhancement. Note, however, that this upforce is still a short-lived translent as far as an indivtdal convecting flux tubes is concerned, being applied for the duration of its transit across the "hot spot" of high $D^{\prime}$ predicted by Lockwood and Fuller-Rowell [1987b], which is typically 5-10 min.

A secondary, much smaller peak in the hydrodynamic mirror force ( $1-1.5 \%$ of gravity) is found in the dawn auroral oval, and this is not so dramatically increased by convection enhancements. However, in this case the flux tubes will convect along the auroral oval and hence remain within the region of enhanced upforce. In this case, the princlpal effect could be an adjustment of the ambipolar field and an increase in the $0^{+}$scale helght. As discussed by Moore $[1980 ; 1984]$ and Lockwood [1984] this can still be a major factor in Ion dynamics by increasing the densities of $\mathrm{O}^{+}$ ions at higher altitudes where the probability of charge exchange with geocoronal hydrogen atoms is reduced and where acceleration mechanisms can drive heavy ion outflows.

\subsection{Comparisons With Ava1lable Observations}

The results presented in Figure 4 are for one set of season/sunspot cycle conditions and a single UT and in a geographic frame of reference. In order fully to contrast with statistical surveys of satellite data on ion flows, averaging of large seasonal and sunspot number bins, and over all UT should be carrled out and the results given in an MLT-invariant latitude frame. However, we can still draw certain parallels, without employing the massive computation time for so many runs of the coupled UCL-Sheffield University model, by noting that the maximum upforce (and Joule heating) is predicted in the convection throat region (before magnetic noon) with a smaller peak in the post-midnight auroral oval. A great many of the statistical surveys of Ionospheric heavy ion upflows show similar features. The survey of DE 1-RIMS data on 0-60 eV (relative to spacecraft potential) $0^{+}$ions by Lockwood et a1. [1985a] shows the pre-noon throat region to be a regular and strong source of $0^{+}$ ions in "upwelling Ion events." Moore et al. [1986a] have studied one such event in detall and found the Ionosperic source to lie within a rapid convection "jet," implying that ion-neutra1 frictional heating and distortions of the lon velocity distribution function may indeed be a factor, as suggested by Lockwood and Fuller-Rowell [1987a]. The comparison of simultaneous data from the DE 1 and 2 satellites by Lockwood et al. [1985c] shows upwelling Ion events originate in upflows of very low energy plasma in the cusp Ionosphere.

Craven et al. [1985] have deduced that this region is also the source of moleculer tons observed in the polar magnetosphere. We note that this calls for an upforce on the molecular lons at very low altitudes, and the hydrodynamic mirror force and collisions with neutral molecules in the presence of strong ion drifts ( $1 . e$. , where $D^{\prime}$ is large) would be a strong candidate for such an upforce.

Studies of nightside auroral ionospheric lon upflows are much more complex, due to the variety of energy ranges, pitch angle distributions and energising altitudes of the lons. Nevertheless, there is a perisistent dawn-dusk asymmetry in the surveys of these flows, similar to that predicted in Figure 4 for the hydrodynamic mirror force. Yau et al. [1985] have evaluated the average upflux of $\mathrm{O}^{+}$lons observed by EICS instrument on DE 1 in the energy range $0.01-1 \mathrm{keV}$ (relative to spacecraft potential). Their study contained data for $\mathrm{Kp}=3-5$ and from two periods which together cover the entire falling phase of the last solar cycle. For both periods the morphology of $0^{+}$flow is the same (see their Figure 4) with peak average flows in the auroral oval which exceed $5 \times 10^{8} \mathrm{~cm}^{2}$ $\mathrm{s}^{-1}$ for the 1500-2100 MLT quadrant (a11 fluxes being normalized to $1000 \mathrm{~km}$ altitude). This dawndusk asymmetry about local midnight is also reported in the occurence frequency of a variety of upflowing low-energy lonospheric ion events: of thermal lons in the topside ionosphere inferred from topside soundings [Lockwood, 1983]; of "transversely accelerated ion" events at energies $>5 \mathrm{eV}$ observed by the ISIS 2 satelitte at $1400 \mathrm{~km}$ [Klumpar, 1979] and of upgoing uni-directional $0^{+}$ flows (energy $>10 \mathrm{eV}$ ) observed by DE 1-EICS [Sagawa et al., 1987]. The dawn-dusk asymmetry in these data has usually been ascribed to a variation in the acceleration mechanism with MLT, usually thought to be associated with the known pattern of fleld-aligned currents which are one possible cause of the acceleration. However, a secondary factor is suggested by Figure 4, in that these observed asymetries in ton outflows could be associated with an MLT variation in the strength of the source of $\mathrm{O}^{+}$lons which feeds lons into the acceleration region.

Considerable upfluxes of lons along the geomagnetic fleld lines have been reported from EISCAT data by Farmer et al. [1984] and Winser et al. [1987a] following increases in Joule heating and rises in ion temperature. These data are from the tristatic RISCAT system; however, the unfavorable viewing geometry and differences in system noise at the three receiving sites makes it difficult to quantify the ion temperature anisotropy in these events. For the event reported by Winser et al. [1988] and Jones et a1. [1988], the observing geometry is 1deal and the 
Joule heating is caused by a reversal of the ion convection from westward to eastward (near the Harang discontinuity) to which the neutral winds cannot respond. The upflows observed by Farmer et a1. [1984] follow a westward convection enhancement due to a geomagnetic substorm. In a similar event, Lovhaug and F1a [1986] were able to employ the tristatic configuration of EISCAT to determine that a large ion temperature anisotropy did Indeed result from the enhanced ion convection. The observations of upflows by winser et al. [1987a] and Farmer et a1. [1984] correspond to the reglons of moderate upforce predicted here for the post-midnight sector under steady state conditions and the afternoon sector following a convection enhancement, and hence do suggest that heating and distribution function changes due to Ion-neutral collisions may indeed be important in driving upflows of ionospheric plasma.

\subsection{Relevance to Models of Ion Upflows}

In this section, we discuss some situations in data analysis and numerical simulations where the assumption of 1sotropic plasma can lead to erroneous results. Consider first the modeling of field-aligned velocity profiles observed by incoherent scatter radar. If the ion temperature antsotropy is neglected (by regarding the fieldaligned temperature measured in the experiment as the average one), the last two terms in (8) cancel and the deduced upward pressure force on the lons will be too small by the amount of the hydrodynamic mirror force. On the other hand, regarding the fleld-parallel ton temperature as equal to a value of the fleld-perpendicular temperature measured, e.g., by a retarding potential analyzer of a low-altitude polarorbiting satellite, is likely to yleld an over estimate of the upward pressure force because typicaliy $T_{1}<T_{\perp}$. Finally, it should be pointed out that the Ion energy equation (12) used in numerical modeling ylelds the average ton temperature $T_{f}$. Assuming 1sotropy and, in particular, that $T_{H}=T_{1}$, will again lead to an erroneous value for the fleld-aligned upforce (probably to an overestimate because we expect $\mathrm{T}_{\text {}}$ $\left(\mathrm{T}_{1}\right)$. We note that Schunk et al. [1975] allowed for anisotropy effects in their study of the plasma density profiles for assumed zero flow at a boundary in the topside lonosphere but did not consider the effects on plasma flows out of the Ionosphere.

Large upflows in assolcation with frictional and Joule heating have been reported by Winser et al. [1988]. To quantify the contribution of the hydrodynamic mirror force to the transient expansion modelled by Gombosi and Killeen [1987] is a nontrivial problem. Let us consider the Initial expansion before the plasma density profile (and hence the ambipolar field) has responded to the heating. By balancing the hydrodynamic mirror force with the Ion-neutral drag force we find that the lon flow relative to the neutral gas will be 1 imited to a few metres per second or less. At greater altitudes, the collision frequency becomes smaller and larger velocitles are possible; however, at some point the approximation scheme discussed in section 1.2 breaks down because the Ion velocity distribution
Is then determined by other effects than ionneutral collisions.

Acknowledgements. The authors are grateful to s. W. H. Cowley for helpful discussions of this work, to the scientists at UCL and Sheffield Untversity who helped develop the coupled 1onosphere-thermosphere model and to the director and staff of EISCAT. EISCAT is supported by the British SERC, French CNRS, West German MPG, Norwegian NAVF, Swedish NFR and Finnish SA. T.J. F-R. Is supported by an SERC advanced Fellowship and K.S. by the Oskari Huttunen Foundation in Finland. The work of M.L. was carried out under a joint appointment between SERC and Imperial College. The Editor thanks Y. T. Chiu and another referee for their assistance in evaluating this paper.

\section{References}

Barakat, A. R., R. W. Schunk, and J.-P. St.Maurice, Monte Carlo calculations of the $0^{+}$ velocity distribution in the auroral Lonosphere, J. Geophys. Res., 88, 3237-3241, 1983.

Chappe11, C. R., T. E. Moore, and J. H. Waite, Jr., The lonosphere as a fully adequate source of plasma for the Earth's magnetosphere, J. Geophys. Res.. 92, 5896-5910, 1987.

Clemmow, P. C. and J. P. Dougherty, Electrodynamics of Particles and Plasmas, Addison-Wesley, Reading, Mass., 1969.

Craven, P. D., R. C. 01sen, C. R. Chappe11, and L. Kakani, observations of molecular ions in the Earth's magnetosphere, J. Geophys. Res., 90, $7599,1985$.

Etemadi, A., S. W. H. Cowley, M. Lockwood, B. J. I. Bromage, D. M. Willis, and H. Luhr, The dependence of high latitude dayside lonospheric flows on the north-south component of the IMF: A high time resolution correlation analysis using EISCAT "Polar" and AMPTE UKS and IRM data, Planet. Space Sc1., 36, 471-487, 1988.

Farmer, A. D., M. Lockwood, R. B. Horne, B. J. I. Bromage, and K. S. C. Freeman, Fleldperpendicular and field-aligned plasma flows observed by EISCAT during a prolonged period of northward IMF, J. Atmos. Terr. Phys., 46, 473$488,1984$.

Farmer, A. D., M. Lockwood, T. J. Fuller-Rowe11, and U. P. L $\phi$ vhaug, Model predictions of the occurrence of non-Maxwellian plasma, and analysis of thelr effects on EISCAT data, J. Atmos. Terr. Phys., 50, 487-499, 1988.

Fulier-Rowe11, T. J., and D. S. Evans, Helghtintergrated Pedersen and Hall conductivity patterns Inferred from the TIROS/NOAA satelitte data, J. Geophys. Res., 92, 7606-7618, 1987.

Fuller-Rowell, T. J., D. Rees, S. Quegan, G. J. Balley, and R. J. Moffett, Interactions between neutral thermospheric composition and the polar ionosphere using a coupled lonospherethermosphere model, J. Geophys. Res., 92, 7744$7748,1987$.

Gombosi, T. I., and T. L. Killeen, Effects of thermospheric motion on the polar wind; A timedependent numerical study, J. Geophys. Res., 92, 4725-4729, 1987.

Heelis, R. A., J. D. Winningham, M. Siguira, and N. C. Maynard, Particle acceleration parallel 
and perpendicular to the magnetic field observed by DE 2, J. Geophys. Res., 89, 3893, 1984.

Heppner, J. P. and N. C. Maynard, High latitude electric field models, paper presented at Chapman Conference on Magnetospheric Currents, AGU, Irving, VA., April 5-8, 1983.

Horwitz, J. L., Core plasma in the magnetosphere, Rev. Geophys., 25, 579-587, 1987.

Horwitz, J. L., and M. Lockwood, The cleft Ion founta1n: A two-dimensional kinetic mode1, J. Geophys. Res., 90, 9749-9762, 1985.

Hubert, D., Non-Maxwellian velocity distribution functions and incoherent scattering of radar waves from the auroral ionosphere, J. Atmos. Terr. Phys., 46, 601-612, 1984.

Jones, G. 0. L., P. J. S. Willlams, K. J. Winser, M. Lockwood and K. Suvanto, Large plasma velocities along the magnetic fleld lien in the auroral zone, Nature, 336, 231-232, 1988.

K1 umpar, D. M. Transversely accelerated 1ons : An Ionospheric source of hot magnetospheric Ions, J. Geophys, Res., 84, 4229,1979.

Lakhina, G. S. and K. G. Bhatla, Ion cyclotron instability in the auroral F-regions, J. Geophys. Res., 89, 9845-9849, 1984.

Lockwood, M., Thermal ion flows in the topside auroral lonosphere and the effects of lowaltitude, transverse acceleration, Planet. Space Sci., 30, 595-609, 1982.

Lockwood, M., Thermospheric control of the auroral source of $\mathrm{O}^{+}$ions for the magnetosphere, J. Geophys. Res., 89, 301-315, 1984.

Lockwood, M., Low-Energy ion flows into the magnetosphere, Adv. Space Res., 6 (3), 63-77, 1986.

Lockwood, M., and T. J. Fuller-Rowe11, The modelled occurrrence of nonthermal plasma in the 1onospheric $F$ region and the possible consequences for ion outflows into the magnetosphere, Geophys. Res. Lett., 14, 371$374,1987 a$.

Lockwood, M., and T. J. Fuller-Rowe11, Correction to "The modelling occurrence of nonthermal plasma in the lonospheric F region and possible consequences for Ion outflows into the magnetosphere," Geophys. Res. Lett., 14, 581$582,1987 \mathrm{~b}$.

Lockwood, M., and J. E. Titheridge, Ionospheric origin of magnetospheric $\mathrm{O}^{+}$lons, Geophys. Res. Lett., 8, 381-384, 1981 .

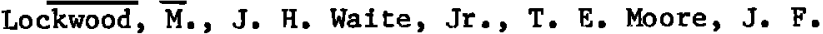
E. Johnson, and C. R. Chappe11, A new source of suprathermal $0^{+}$ions near the dayside polar cap boundary, J. Geophys. Res., 90, 4099-4116, $1985 a$.

Lockwood, M., M. O. Chandler, J. L. Horwitz, J. H. Walte, Jr., T. E. Moore, and C. R. Chappell, The cleft Ion fountain, J. Geophys. Res., 10 , 9736-9748, 1985b.

Lockwood, M., T. E. Moore, J. H. Waite, Jr., C. R. Chappe11, J. L. Horwitz, and R. A. Heelis, The geomagnetic mass spectrometer-Mass and energy disperstons of lonopheric lon flows into the magnetosphere, Nature, 316, 612-613, $1985 \mathrm{c}$.

Lockwood, M., A. P. van Eyken, B. J. I. Bromage, D. M. Willis, and S. W. H. Cowley, Eastward propagation of a plasma convection enhancement following a southward turning of the interplanetary magnetic field, Geophys. Res. Lett., 13, 72-75, $1986 \mathrm{a}$.
Lockwood, M., A. P. van Eyken, B. J. I. Bromage, J. H. Waite, Jr., T. E. Moore, and J. R. Doupnik, Low-energy outflows from the Ionosphere during a mafor polar cap expansionEvidence for equatorward motion of inverted- $V$ structures, Adv. Space Res., 6(3), 93-101, $1986 \mathrm{~b}$.

Lockwood, M., B. J. I. Bromage, R. B. Horne, J.-P. St.-Maurice, D. M. Willis, and S. W. H. Cowley, Non-Maxwellian ion velocity distributions observed using EISCAT, Geophys. Res. Lett., 14, 111-114, 1987.

Lockwood, M., K. Suvanto, J.-P. St.-Maur1ce, K. Kikuch1, B. J. I. Bromage, D. M. Will1s, S. R. Crothers, H. Todd, and S. W. H. Cowley, Scattered power from non-thermal F-region plasma observed by EISCAT-Evidence for coherent echoes?, J. Atmos. Terr. Phys., 50, 467-486, $1988 \mathrm{a}$.

Lockwood, M., M. F. Smith, and G. L. Siscoe, Ionospheric ion upwelling in the wake of flux transfer events at the dayside magnetopause, $\mathrm{J}_{\text {. }}$ Geophys. Res., 93, 5641-5654, 1988b.

L $\phi$ vhaug, U. P., and T. F1A, Ion temperature anisotropy in the auroral $\mathrm{F}$ region as measured with EISCAT, J. Atmos. Terr. Phys., 48, 959$971,1986$.

Moorcroft, D. R., and K. Schlegel, Evidence for non-Maxwellian velocity distributions in the Fregion, J. Atoms. Terr. Phys., 50, 455, 1988.

Moore, T. E., Modulation of terrestrial escape flux composition (by low-altitude acceleration and charge exchange chemistry), J. Geophys. Res., 85, 2011-2116,1980.

Moore, T. F., Superthermal Ionospherlc outflows, Rev. Geophys. Space Phys., 22, 264-274, 1984.

Moore, T. E., M. Lockwood, M. 0. Chandler, J. H. Walte, Jr., C. R. Chappe11, A. Persoon, and M. Suguira, Upwelling $0^{+}$ion source characteristics, J. Geophys. Res., 19, 7019$7031,1986 a$.

Moore, T. E., C. J. Pollock, R. L. Arnold, and P. M. Kintner, Preferential $0^{+}$heating in the topside Ionsphere, Geophys. Res. Lett., 13, 901-904, 1986b.

Ott, E. and D. T. Farley, Microinstabilities and the production of short-wavelength irregularities in the auroral $\mathrm{F}$ region, $\mathrm{J}$. Geophys. Res., 80, 4599-4602, 1975.

Raman, R. S. V., J.-P. St.-Maurice, and R. S. B. Ong, Incoherent scattering of radar waves in the auroral Ionosphere, J. Geophys. Res., 86, 4751-4762, 1981.

Rees, D., R. Gordon, T. J. Fuller-Rowell, M. F. Smith, G. R. Carignan, T. L. Killeen, P. B. Hays, and N. W. Spencer, The composition, structure, temperature and dynamics of the upper thermosphere in the polar regions during October to December 1981, Planet. Space Sc1., $33,627-666,1985$.

Rishbeth, H., P. R. Smith, S. W. H. Cowley, D. M. Willis, A. P. van Eyken, B. J. I. Bromage, and $S$. R. Crothers, Ionospheric response to changes in the interplanetary magnetic field observed by EISCAT and AMPTE-UKS, Nature, 318, 415-416, 1985.

Roux, D., J. J. Berthelier, V. A. Gladyshev, I. V. Zinin, V. D. Maslov, and M. L. Plvovarov, Vertical transport of $0^{+}$ions at high latitudes, in Results of the ARCAD-3 Project and of the Recent Programmes in Magnetospheric 
and Ionospheric Physics, p.381, France Cepadues, Toulouse, 1985.

Sagawa, E., A. W. Yau, B. A. Whalen, and W. K. Peterson, Pitch angle distributions of lowenergy fons in the near-Earth magnetosphere, $\mathrm{J}$. Geophys. Res., 92, 12,241-12,254, 1987.

Schunk, R. W., W. J. Raitt, and P. M. Banks, Effect of electric fields on the daytime highlatitude $E$ and $F$ regions, J. Geophys. Res., 80 , 3121-3130, 1975.

Siscoe, G. L., and T. S. Huang, Polar cap inflation and deflation, J. Geophys. Res., 90, 543-547, 1983.

St.-Maurice, J.-P., On a mechantsm for the formation of VLF electrostatic emissions in the high latitude $F$ region, Planet. Space Sc1., 26, 801-816, 1978 .

St.-Maurice, J.-P., W. B. Hanson and J. C. G. Walker, Retarding Potential Analyzer Measurement of the effect of ion-neutral collisons on the fon velocity distribution in the aurora1 lonosphere, J. Geophys. Res., 81 , 5438-5446, 1976.

St.-Maurice, J.-P, and R. W. Schunk, Ion velocity distributions in the high-latitude lonosphere, Rev. Geophys. Space Phys., 17, 99-134, 1979.

Suvanto, K., Ion cyclotron microlnstability driven by non-thermal F-region plasma, Planet. Space Sci., In press, 1988a.

Suvanto, K., Microinstabilities driven by nonthermal plasma in the high-latitude F-region, Adv. Space Res., in press, $1988 \mathrm{~b}$.

Todd, H., B. J. I. Bromage, S. W. H. Cowley, M. Lockwood, A. P. van Eyken, and D. W. Willis, EISCAT observations of bursts of rapld flow in the high-1atitude dayside ionosphere, Geophys. Res. Lett., 13, 909-912, 1986.

Tsunoda, R., R. C. Livingston, C. L. Rino, and J. F. Vickrey, Dayside observations of thermal Ion upwelling at $800 \mathrm{~km}$ altttude: An lonospheric signature of the cleft lon fountaln, EOS, Trans. AGU, 66(46), 1003, 1985.
Whalen, B. A., W. Bernste1n, and P. W. Daly, Low altitude acceleration of ionospheric lons, Geophys. Res. Lett., 5, 55, 1978.

Winser, K. J., G. O. L. Jones, and P. J. S. Willams, Varlations in fleld-aligned plasma velocity with altitude and latitude in the auroral zone: EISCAT observations and physical interpretation, Phys. Scr., 37, 640-644, 1987a. Winser, K. J., M. Lockwood, and G. O. L. Jones, Nonthermal plasma observations using EISCAT: Aspect angle dependence, Geophys. Res. Lett., $14,957-960,1987 \mathrm{~b}$.

Winser, K. J., G. 0. L. Jones, P. J. S. Williams and M. Lockwood, Observations of large fieldaligned flows of thermal plasma in the auroral Ionosphere, Adv. In Space Res., In press, 1988.

Yau, A. W. and M. Lockwood, Vertical lon flow in the polar lonosphere, in "Modeling Magnetospher 1c Plasma", Geophys. Monogr. Ser., 44, AGU, Washington, D.C., 229-240, 1988.

Yau, A. W., B. A. Whalen, A. G. McMamera, P. G. Kellog, and $W$. Bernstein, Particle and wave observations of low altitude lonospheric ion acceleration events, J. Geophys. Res., 88, 34, 1983.

Yau, A. W., E. G. Shelley, W. K. Peterson, and L. Lenchyshyn, Energetic auroral and polar ion outflow at DE 1 altitudes: Magnitude, composition, magnetic activity dependence, and long term varlations, J. Geophys. Res., 90, 8417-8432, 1985.

T. J. Fuller-Rowell, Untversity College, Gower Street, London, WC1E 6BT England.

M. Lockwood, Rutherford Appleton Laboratory, Chilton, Didcot, OX11 OQX England.

K. Suvanto, Blackett Laboratory, Imperial College, London, SW7 2BZ, England.

(Recelved October 14, 1987; revised April 29, 1988; accepted June 16, 1988.) 